\title{
The Politics of Legal Empirics: Do Political Attitudes Predict the Results of Empirical Legal Scholarship?
}

\author{
by \\ Jeffrey J. Rachlinski*
}

\begin{abstract}
Empirical legal scholarship has emerged as a dominant trend in legal scholarship. At its best, empirical scholarship subjects assertions about the effect of legal rules to a neutral test. But is empirical inquiry truly neutral? The validity of an empirical study should rest on the reliability of the methods used, rather than the political implications of its conclusions. Scholars might choose targets of inquiry, sources of data, or methods of analysis that support their political allegiances. This paper tests this thesis by matching the political beliefs of authors of empirical legal scholarship with the results of their research. The political allegiances of authors mildly correlate with the results of empirical inquiry in legal scholarship.
\end{abstract}

Keywords: empirical legal scholarship

JEL classification code: $\mathrm{A} 10, \mathrm{C} 10$

\section{Introduction}

Distrust marks our age. Skepticism of political institutions in many countries has never been higher. Poll after poll in the United States shows eroding support for every institution of government - the legislature, the administrative state, law enforcement, the Presidency, and even the courts (see Wilke, 2013). Lack of confidence in the institutions of the state might represent nothing more than an uptick in a long-term trend. Distrust, however, has infected views of private bulwarks of any modern liberal state such as the media and the scientific community. Long gone are the days when the nightly news anchor Walter Cronkite was "the most trusted man in America." Today, allegations of "fake news" accompany almost every major news event in the United States. Unadulterated respect for the scientists who landed human beings on the moon, too, has turned into "climate skepticism." Many believe scientists fabricate results to suit their own political agendas. Growing distrust has shaken political institutions across the globe, leading to the election of Donald Trump, Great Britain's withdrawal from the European Union, and inroads by right-wing parties once thought to be politically marginal. Where politicians

\footnotetext{
* Cornell Law School, Ithaca (NY), U.S.A.
} 
once disagreed on what constitutes a sound policy, now entire societies disagree about what even constitute a fact.

Skepticism of society's once-trusted institutions has a plausible foundation. The sciences - particularly the social sciences - have witnessed a growing series of crises that undermine their impartiality. Growing reports of connections between researchers and pharmaceutical companies undermine faith in the medical sciences. The medical sciences have also witnessed problems with the replicability of research results thought to be foundations of contemporary medicine (see Leek and Peng, 2015). Some notable climate scientists also made mistakes in reporting research - mistakes that to most of the scientific community seemed minor, but which gave skeptics of climate science a bellows with which to fan the flames of climate denial (see Editorial, 2010). Psychology has been hit from three sides: a prominent Dutch researcher was forced to admit to completely fabricating data (see Bhattacharjee, 2013); numerous reports have surfaced that a great many psychologists use data-collection or reporting methods that lead to unreliable conclusions, leading to a veritable cottage industry of researchers who spend their time simply debunking work by others (see Simmons, Nelson, and Simonsohn, 2011); and finally comes a highly visible collaborative study that purports to show that $75 \%$ of all social psychological findings reported in its most prestigious journal do not replicate (Open Science Collaboration, 2015).

The empirical legal studies movement stands in stark contrast to the growing skepticism about scientific research. Just as the general public seems to be losing faith in science, legal scholars have embraced empirical approaches as never before. Empirical scholarship now regularly fills law reviews, and law faculties have hired large numbers of empirical scholars (see Heise, 2011). Empirical legal research holds out the promise of advancing understanding of legal systems in a nonpartisan fashion. For issues such as whether the death penalty deters crime, whether gun ownership deters crime, or whether medical malpractice litigation is out of control, an empirical approach holds out the promise of an accurate, politically neutral resolution. The move towards empirical scholarship in law likely stems from the rise in the number of social science $\mathrm{PhDs}$ hired by the legal academy, the widespread availability of public data sets through the Internet, and access to user-friendly statistical software (see Rachlinski, 2011). The latter two trends have influenced the sciences, of course, but not nearly to the extent that they have influenced law, leading to the curious paradox that just as society's skepticism of empirical work grows, law has embraced it.

Although empirical work has proliferated within the legal academy, it remains encumbered by the same skepticism that science faces more broadly. Rarely does empirical work in law provide a definitive resolution to any important question. Typically one can find research cutting in opposite directions (see Rachlinski, 2016). On hot-button social issues such as the deterrent effect of the death penalty or the influence of gun ownership on crime, one can find an equal array of empirical studies on opposite sides of the issue. Political partisans can thus find support for their own positions in the array of empirical scholarship. Indeed, studies show 
that exposing partisans to a mixed array of evidence serves only to strengthen their prior beliefs (Lord, Ross, and Lepper, 1979). Partisans embrace work that supports their views - finding it methodologically sound - even as they reject work that undermines their views - finding it methodologically defective. Social psychologists call this phenomenon biased assimilation.

Biased assimilation can drive a researcher crazy. Faced with conflicting empirical results, researchers committed to a scientific approach try to sort through the studies to identify the sources of inconsistency. Perhaps competing studies use different data sets, or adopt different statistical approaches. Rejecting studies that are incompatible with one's political views while accepting those that are not is simply not part of good empirical scholarship. And yet it is clear that biased assimilation is a dominant approach among laypeople, at least (see Kahan and Braman, 2003). Research that is not congenial to one's politics tends to get ignored or heavily criticized.

Frustrating though biased assimilation can be for researchers, is it truly irrational? Empirical research might not be as neutral as scholars hope. The political views of those who conduct empirical research might affect several steps in the research agenda. First, political views might influence scholars' choice of topics. For example, the debate as to whether an increase in gun ownership can reduce crime levels is a topic that conservative scholars created. On the other side of the coin, many studies of the hidden influence of race on decision making, such as whether people suffer from a "shooter bias" in that they are more inclined to shoot AfricanAmerican than white targets in a video-game style program (Correll et al., 2002), or whether people are willing to pay more in online sales of goods owned by white sellers than by African-Americans (Ayres, Banaji, and Jolls, 2015), seem like the product of more liberal concerns. Some research, of course, would be of interest to anyone in the political range. For example, determining whether the availability of the death penalty deters murder would be of interest to conservatives (for whom faith in the deterrent effect of capital punishment is important), and to liberals (who believe that capital punishment does not deter). Topic selection, however, is apt to have political motives behind it.

Secondly, choice of a data set can be influenced by political views. Liberal scholars might well be more inclined to trust (at least some) government statistics. For example, using my own scholarship, I used data collected by the United States Fish and Wildlife Service to assess whether the Endangered Species Act is effective in increasing the chances that species will survive (Rachlinski, 1997). According to those data, the Act is effective. Critics of that conclusion argued that a governmental agency would naturally produce data that supported its own program, and urged me to use private sources of data on species populations, such as the National Audubon Society's annual Christmas bird count, or data from private conservation groups like Hawk Mountain. I could not find enough data from such sources to support an acceptable analysis, but the point is a good one.

Third, a researcher might analyze the data in a way that tends to support their prior beliefs. Complex empirical data sets require judgment calls as to what to 
include or exclude, or what models to assess and report. Typically, no clear analytic method stands out as uniquely correct. Researches might be more apt to choose methods that produce results that are more congenial to their political attitudes.

Jay Koehler has demonstrated a tendency to react to methodology in a basal fashion, albeit in a somewhat different context (Koehler, 1993). He asked several hundred psychologists and parapsychologists to assess a study that purported either to show or to disprove the influence of extrasensory perception in a standard task within the parapsychological literature. (The study purported to be real, but was fabricated.) Not surprisingly, he found that when the study supported the researchers' prior beliefs about ESP, they found it more convincing. More surprisingly, the study participants also criticized the appropriateness of the statistical analysis used in the study when its conclusions contradicted their prior beliefs about ESP. Although Koehler's work does not review political attitudes, his results showed that choice of statistical methodology can be influenced by attitudes.

Finally, some researchers might be engaged in unethical practices or outright academic fraud to produce political results that support their political agendas. Although academic fraud is uncommon, it is not unheard of. Researchers might quietly eliminate outliers from their data set, engage in selective coding methods, or even (in the worst cases) simply fabricate data.

A previous study by Adam Chilton and Eric Posner revealed that political orientation correlates with conclusions in legal scholarship (Chilton and Posner, 2015). These authors sampled ten legal scholars from each of 14 top law schools in the United States and had five law students review and rate five of their recent publications as favoring liberal or conservative positions, or as having no clear political position. The authors then used these ratings to identify the political orientation of each faculty member's scholarship as a whole. Chilton and Posner then identified any contributions to political campaigns each of these authors made using the same database that I used in the present analysis (see below). They found that law professors who have donated to Democrats produced more articles favoring liberal positions than those who have donated to Republicans, and vice versa. They also found that scholars writing in constitutional law express more political bias than in other fields. Importantly to the present study, they also found the same tendencies among faculty members who hold $\mathrm{PhDs}$ in social sciences, which suggests that empirical work is not immune to the influence of political bias.

Indeed, in other empirical fields, scholars argue that political bias affects research output. Economists contend that bias influences their field (see, e.g., Gordon and Dahl, 2013), although direct evidence is sparse. Jelveh, Kogut, and Naidu provide the clearest evidence, showing that political views shape the language and conclusions of economics, influencing what economists study and how they study it. ${ }^{1}$ Some psychologists have argued that the lack of political diversity in the field directs research, undermines the validity of the field, and even contributes to the

\footnotetext{
${ }^{1}$ Zubin Jelveh, Bruce Kogut, and Suresh Naidu, "Political Language in Economics," unpublished manuscript on file with the author.
} 
lack of replicability of research findings (Duarte et al., 2015). Although these authors show that psychology lacks political diversity, they also fail to identify direct evidence. Rathbun found that political scientists embrace different approaches depending upon their ideology, but this study is also a survey of attitudes rather than of publications (Rathbun, 2012). Other than the recent piece by Jelveh et al., these commentators lack the kind of evidence that Chilton and Posner provide for legal scholarship. That is, research in the relevant empirical social sciences does not directly correlate publication bias with political bias. The question thus remains whether politics washes out in the empirical crucible, or whether political bias influences the outcome of empirical work.

This paper tests whether the political affiliations of authors of empirical legal scholarship correlate with the political implications of their results. To assess this I evaluate ten years of publications in the Journal of Empirical Legal Studies and The Journal of Legal Studies. I also use political contributions of the authors as a means of identifying their political orientation.

\section{Method: The Articles}

As the data set, I chose ten years of publications in Journal of Empirical Legal Studies (JELS) and The Journal of Legal Studies (JLS), from 2007 to 2017. JELS is completely dedicated to the publication of empirical legal scholarship. (In the interests of full disclosure, I am among the founding editors of JELS and was an editor throughout the ten-year period.) JLS is older and is not limited to empirical work, although in recent years, a high proportion of its output has consisted of empirical scholarship. The editors at JELS are all members of the Cornell law faculty (although it has a board that includes scholars with a wide range of affiliations), and the editors at JLS are all members of the University of Chicago law faculty. Although both journals publish scholarship by law-school faculty members, both also publish numerous articles produced by scholars who are not law professors (economists, business school professors, and other social scientists).

I chose these two journals as targets for several reasons. Notably, they are peerreviewed journals dedicated to legal scholarship. Most law publications are edited by students, and hence lack the kind of scrutiny (for good or for ill) that peer review produces. I avoided other peer-reviewed journals that publish legal scholarship, as most are specialized in particular subjects within law. I also avoided using the Law \& Society Review, which includes a large amount of empirical work that is qualitative in nature.

I coded the articles for their political content. I chose this method, rather than having outsiders such as law students do the coding, out of concern as to whether students could truly sort the empirical work by politics without close micromanagement. Students might be unaware of the political implications of various aspects of medical malpractice reform, or the concerns business groups (and hence Republicans) have about the use of civil juries. This method has a disadvantage in that 
I was not completely blind to the political orientation of the authors. To alleviate that, I coded the papers before identifying the political contributions of the authors. I nevertheless certainly had strong priors about what I would find for many of the authors (whom I know or whose writing I know), and this could have influenced the results. I identify the basic rules for categorization that I followed below. The full spreadsheet with articles identified and coding system is available upon request.

The articles addressed dozens of different issues. Each was scored as supporting Democratic positions, supporting Republican positions, neutral, or addressing foreign (non-U.S.) subject. Articles were scored as favoring Democratic positions if the results:

(a) supported the efficacy of a regulatory intervention.

(b) generally supported the effectiveness of litigation, either by supporting the efficacy of individual civil litigation in deterring misconduct or negligence, by supporting the reliability of juries, by supporting the role of trial lawyers as effective and efficient, or by suggesting that courts are biased against individual plaintiffs in favor of corporate interests.

(c) demonstrated racial disparities in criminal or civil justice.

Articles were scored as favoring Republicans if the results:

(a) demonstrated the efficacy of private regulation or self-regulation over governmental intervention in markets, or otherwise supported the efficiency of market solutions or inefficiency of regulatory intervention.

(b) suggested that litigation is wasteful or inefficient (for example, by encouraging defensive medicine), that arbitration is more efficient than litigation, or that jury decision making is erratic or unreliable.

(c) indicated that more aggressive policing, prosecution, or incarceration is effective at reducing crime.

Several articles were purely descriptive of one aspect of legal rules in a way that could not reasonably be aligned with the position of either political party. Several papers, for example, described aspects of the patent system that could not easily be said to support one position or another.

Articles that addressed foreign issues were largely excluded from the analysis, as were papers produced entirely by foreign authors. On occasion, some of the foreign articles directly addressed domestic U.S. issues (for example, a paper describing the lack of a deterrent effect of the death penalty in China). In the rare instances in which this occurred, and the articles included domestic authors, they were included. Foreign scholars were excluded because the political orientation of the authors was assessed with political contributions and only American citizens may make such contributions. $^{2}$

2 Some scholars who reside in the United States are not citizens, but they have been kept in the analysis (and are scored as not politically aligned). 


\section{Method Part II: Identifying Political Attitudes}

To identify the political commitments of the authors, I relied on contributions to political candidates in the United States. These contributions are publicly available in searchable databases, and have been used in other research. ${ }^{3}$ For this study, I used opensecrets.org - a website maintained by the Center for Responsive Politics. The website reports every political contribution made at the federal level to candidates and political organizations since 1998. The site is searchable by individual donor, and includes the donor's name, residence (by ZIP code), employer, and occupation (the last two pieces of information are occasionally missing). The site identifies to whom the donation was made, the date of the donation, the amount of the donation, and the party affiliation of the recipient.

To identify the political contributions of the scholars, I entered the name of the author in the opensecrets search engine (omitting the middle name, which is not always present in the opensecrets database). If the database found no matches to that name, then I coded that author as having made no political contributions. If the database did match the name, then I investigated further to ascertain whether the name identified in the database corresponded to the name of the author, by examining the location and employer associated with the name. In most cases, a match was obvious (for example, the name identified a town near the university and identified the author's home institution as the donor's employer). I also used variations on the author's first name (e.g., Bob and Robert), although more formal names tend to be the norm in the database.

This method appeared to be highly reliable. In most cases, either no record matched that of the author's name or multiple records appeared that included the university (and unit, such as the law school) as employer. Some cases required further inquiry. Some more common names naturally included multiple matches. Most could be ruled out based on employment. When employment was not available, the rest could largely be eliminated based on location. In some cases I had to search multiple states to identify all likely locations (e.g., an NYU faculty member could live in New York, New Jersey, or Connecticut - conceivably further afield, but I ignored remote possibilities.) In a few instances, in which the donor matched first and last names with an author, no middle name was listed, no employer was listed, and the geographic location was plausibly within commuting distance of the author's institution, I had to investigate the donor further, using white pages to identify the donor's likely middle name. Also, for older donations, I checked the authors' employment history on their CV to see if a previous employer and location matched a previous donation. I did not investigate the donations of authors based outside of the United States (which are illegal under U.S. law), coding them as "international." If there are errors in the matching method, they are most likely that of omission. Authors who have changed names or who have common names and donated only many years earlier might have been missed.

3 See Chilton and Posner (2015, supra) for a review. 
For example, one difficult author was Robert B. Thompson, of Georgetown (an author I much admire and respect), formerly of Vanderbilt. Reviewing how I identified him gives a good example of the method. The name is common, and the database included over three thousand entries attributed to "Robert Thompson" and 48 attributable to Robert B. Thompson (I also repeated the process using "Bob"). Three of these donations are clearly Professor Thompson's, as the records list Vanderbilt Law School as the donor's employer. That is straightforward, but further investigation was necessary to ensure I identified all of Professor Thompson's donations. The other 45 donations identified people from other parts of the country, with other employers (none of which are universities). Searching for "Robert Thompson" (without the middle name) in Tennessee, the District of Columbia, Maryland, and Virginia revealed a few donations - to Republicans - by people with that name who did not list their middle name and did not list their employer. Although it is possible that some of these donations are from Professor Thompson, it is unlikely that I would misclassify his donation pattern, for two reasons. First, I assume people mostly (although there are clearly exceptions) complete the donor form in a similar fashion, so that once someone is listed with a middle name in the database, they will tend to keep that name (hence there are not likely to be any donations by Professor Thompson that do not identify him as Robert B. Thompson). Second, donations to different parties were uncommon. Indeed, I only identified four authors who had donated to both parties (I scored these as neutral, as if they had never donated). I thus listed Robert Thompson as a Democrat with some measure of confidence.

This method has limitations. First, it is underinclusive. Most people (and academics are no exception) have never donated to any political candidate, even though most Americans identify with either the Republicans or the Democrats. It also does not capture donations at the state or local level. Second, it can be overinclusive. A single donation could be idiosyncratic. That said, the database identifies many people who feel strongly enough about politics to put their money behind their political attitudes.

\section{Results}

The ten years of JELS publications consisted of 305 empirical articles (and 2 commentaries that were not included) produced by 692 authors (509 unique authors, after taking account of multiple publications). This time period included 95 empirical articles in JLS produced by 193 authors (158 unique authors). In total, the data include 400 articles produced by 885 authors, 636 of whom are unique.

The 885 authors included 171 foreign authors. (Note that for this paragraph, an author who published multiple articles is counted multiple times.) Excluding these authors, $21 \%$ had contributed exclusively to Democrats, $5 \%$ exclusively to Republicans, $1 \%$ to both, and the remaining $73 \%$ to none. Excluding the 72 foreign articles left a total of 328 articles in the database. Of these articles $38 \%$ were iden- 
Figure

Percentage of Papers Supporting Democratic, Republican, or Neutral Positions by Party of Authors

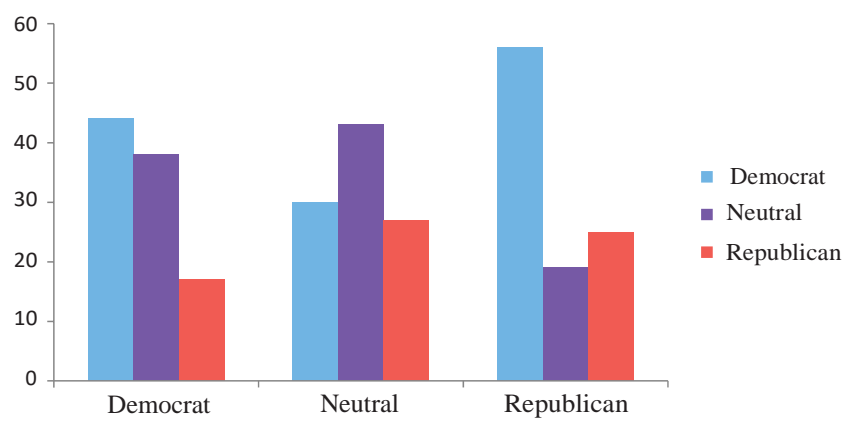

tified as supporting Democratic positions, $39 \%$ as neutral, and $24 \%$ as supporting Republican positions.

I categorized the authorship of an article as Democratic if at least one author was a Democratic contributor and it also had no Republican contributors as authors. This amounted to 115 articles (35\%). I categorized the authorship as Republican if at least one author was a Republican contributor and it also had no Democratic contributors as authors. This amounted to 32 articles (10\%). The data also include 179 articles $(55 \%)$ in which none of the authors had contributed to either party (or an author had contributed to both). Two papers had authors who had contributed to different parties (one of these articles supported a Democratic position and the other a Republican position), and these are excluded from the analysis below.

Politics correlated with authorship. Among the 115 articles that had at least one author who had contributed to Democratic causes, 51 articles (44\%) drew conclusions that supported Democratic positions, 44 (38\%) were neutral, and 20 (17\%) supported Republican positions. In contrast, among the 32 articles that had at least one author who had contributed to Republican causes, 18 articles (56\%) drew conclusions that supported Democratic positions, 6 (19\%) were neutral, and $8(25 \%)$ supported Republican positions. Among the 179 articles with no authors who had contributed to either party, 53 papers $(30 \%)$ drew conclusions that supported Democratic positions, 77 (43\%) were neutral, and 49 (27\%) supported Republican positions. The results are displayed in the figure.

The Democratic authors exhibited a statistically significantly different pattern from the neutral authors, $x^{2} .2 / D 7: 66, p$ D0:02. The Democrats favored Democratic positions and disfavored Republican positions more than the neutral authors, as one would expect if politics affected scholarship. The Republican authors also differed from the neutral authors, $x^{2} .2 D 9: 85, p$ D:007, but in an unexpected direction. The Republican authors favored Democratic positions more than the neutral authors. 


\section{Discussion}

The results support the view that politics influences scholarship, although the effects were somewhat surprising. The Democratic authors favored positions taken by the party to which they had contributed, at least in comparison with those authors who had never contributed to any party. The Republicans, however, exhibited the curious pattern of favoring Democratic positions more than the neutrals did. Indeed, the Republicans were about as favorable to Democratic positions as were the Democratic authors.

What would explain these results? Partisanship is perhaps best explained by one of the mechanisms described above - notably, choice of topic or methods. Alternative explanations are possible. Democrats might well point to the results among Republicans as evidence that the positions taken by the Democratic Party reflect reality more than those taken by the Republican Party. The results among the neutral authors suggest the contrary, however. The neutral authors produced more neutral papers, but also a balance between Democratic and Republican outcomes. That said, Democrats might further contend that the neutral authors avoid partisan issues, in comparison with those who have donated to parties. If so, then it is possible that among the more partisan issues, empirical scholars of both parties tend to support Democratic positions.

The results have limitations, of course. Most of the authors have never contributed to either party, but likely they have political allegiances. Previous research indicates that the legal academies have many more Democrats than Republicans (see McGinnis, Schwartz, and Tisdell, 2005). Given the 4\|1 ratio of Democratic to Republican contributors in this sample, many of the neutrals are probably actually Democrats. That said, those who contribute might well be more partisan than those who do not, and in these data, they exhibited a different pattern of results. Furthermore, in a similar study, Chilton and Posner also added data from CVs of authors to classify many of the authors who had not contributed to either party, and found that doing so did not change their results (Chilton and Posner, 2015, supra).

The study is also limited to two journals, for the reasons explained above. A broader swath of publications might yield a different result. Furthermore, the publication record of these journals is likely to be influenced by their editorial boards. Editorial bias could also skew scholarship, of course. The editors of these two journals throughout this period include one person who has contributed to Democrats and two who have contributed to Republicans. These two journals were also chosen as leaders in publishing a broad range of quantitative empirical research on law. If empirical scholarship can be neutral, it should be neutral in these journals.

It is worthwhile comparing the results obtained here with those of Chilton and Posner (2015). Chilton and Posner found bias among both sides - Republican legal scholars favored Republican positions and Democratic legal scholars favored Democratic positions. I found only bias among the Democrats and cannot replicate Chilton and Posner's result among Republicans. The two studies have several methodological differences. First, the sample is different. Many authors from eco- 
nomics departments, political science departments, psychology departments, business schools, medical schools, and nonuniversity institutions publish in JELS and JLS, whereas Chilton and Posner relied entirely on law professors. Second, Chilton and Posner used a continuous measure, rather than a tripartite distinction. (Such a difference, though, would be unlikely to change the dramatic results in the present analysis, given the distinct trends in the data.) Finally, they used students to code the data, which might have produced a different result from the one I obtained with my own coding.

Is bias a problem? Evidence of bias should be of greater concern to empirical legal scholars than to scholars who do not collect data to test their conclusions. Empirical scholars strive for objectivity, whereas many conventional legal scholars can defend the idea that they are, in part, advocates. Many scholars do not pretend to be neutral, and openly embrace particular perspectives. Empirical scholars are comfortable as advocates as well, but only up to a point. Partisans might sensibly pick topics to study that are congenial to their policy preferences. But the choice of data or methods should be guided by norms of the profession and not politics. These data cannot sort whether the observed bias among the Democratic authors arises from topic selection or more troublesome tendencies. The results, however, raise the specter that empirical work is not so neutral.

If bias in empirical scholarship is a problem, what can be done about it? These data cannot answer that question either. No obvious pattern of suspect methods or data sources emerges from casual examination of the data. Most of the data in the articles are publicly available data analyzed by multivariate regression. The articles also include numerous experimental papers, which tend to produce neutral results, but that fact largely arises from topic selection. Notably the data include several studies of experimental game theory that cannot meaningfully be categorized by politics. Given the limits of experimental work and the need to test out theories in the field for law, this result should not be taken as a recommendation to publish fewer studies using public data and more using experimental data. Neither does it seem that peer review and robust review of methodology - which are features of both journals - will be a cure, since the results were obtained with articles that were subjected to peer review. Should these results be replicated with other approaches, empirical legal scholarship might find it necessary to live with the idea that it is less objective than its proponents would like.

\section{References}

Ayres, Ian, Mahzarin Banaji, and Christine Jolls (2015), "Race Effects on eBay," The RAND Journal of Economics, 46(4), 891-917.

Bhattacharjee, Yudhijitt (2013), "The Mind of a Con Man," The New York Times, April 26, p. MM44.

Chilton, Adam S., and Eric A. Posner (2015), "An Empirical Study of Political Bias in Legal Scholarship,” The Journal of Legal Studies, 44(2), 277-314. 
Correll, Joshua, Bernadette Park, Charles M. Judd, and Bernd Wittenbrink (2002), “The Police Officer's Dilemma: Using Ethnicity to Disambiguate Potentially Threatening Individuals," Journal of Personality and Social Psychology, 83(6), 1314-1329.

Duarte, José L., Jarret T. Crawford, Charlotta Stern, Jonathan Haidt, Lee Jussim, and Philip E. Tetlock (2015), "Political Diversity Will Improve Social Psychological Science," Behavioral and Brain Sciences, 38, e130, DOI: 10.1017/S0140525X14000430.

Editorial (2010), "Closing the Climategate," Nature, 468(7322), 345.

Gordon, Roger, and Gordon B. Dahl (2013), "Views among Economists: Professional Consensus or Point-Counterpoint?" The American Economic Review, Papers \& Proceedings, 103(3), 629-635.

Heise, Michael (2011), “An Empirical Analysis of Empirical Legal Scholarship Production, 1990-2009," The University of Illinois Law Review, (5), 1739-1752.

Kahan, Dan M., and Donald Braman (2003), "More Statistics, Less Persuasion: A Cultural Theory of Gun-Risk Perceptions," University of Pennsylvania Law Review, 151(4), 1291-1328.

Koehler, Johnathan J. (1993), "The Influence of Prior Beliefs on Scientific Judgments of Evidence Quality," Organizational Behavior and Human Decision Processes, 56(1), 28-55.

Leek, Jeffrey T., and Roger D. Peng (2015), "Reproducible Research Can Still Be Wrong: Adopting a Prevention Approach," Proceedings of the National Academy of Sciences (PNAS), 112(6), 1645-1646.

Lord, Charles G., Lee Ross, and Mark R. Lepper (1979), "Biased Assimilation and Attitude Polarization: The Effects of Prior Theories on Subsequently Considered Evidence," Journal of Personality and Social Psychology, 37(11), 2098-2109.

McGinnis, John O., Matthew A. Schwartz, and Benjamin Tisdell (2005), "The Patterns and Implications of Political Contributions by Elite Law School Faculty," Georgetown Law Journal, 93(4), 1167-1212.

Open Science Collaboration (2015), "Estimating the Reproducibility of Psychological Science," Science, 349(6251), aac4716.

Rachlinski, Jeffrey J. (1997), "Noah by the Numbers: An Empirical Evaluation of the Endangered Species Act,” Book Review, Cornell Law Review, 82(2), 356-389.

- (2011), "Evidence-Based Law," Cornell Law Review, 96(4), 901-924.

- (2016), "Does Empirical Evidence on the Civil Justice System Produce or Resolve Conflict?" DePaul Law Review, 65(2), 635-654.

Rathbun, Brian (2012), "Politics and Paradigm Preferences: The Implicit Ideology of International Relations Scholars,” International Studies Quarterly, 56(3), 607-622.

Simmons, Joseph, Leif D. Nelson, and Uri Simonsohn (2011), "False-Positive Psychology: Undisclosed Flexibility in Data Collection and Analysis Allows Presenting Anything as Significant," Psychological Science, 22(11), 1359-1366.

Wilke, Joy (2013), “Americans' Satisfaction with U.S. Gov’t Drops to New Low,” Gallup, October 10, http://news.gallup.com/poll/165371/americans-satisfaction-gov-drops-new -low.aspx, accessed October 31, 2017.

Jeffrey J. Rachlinski

Cornell Law School

122 Myron Taylor Hall

Ithaca, NY 14853-4901

U.S.A.

jjr7@cornell.edu 